\title{
General and cancer specific mortality of a population based cohort of patients with inflammatory bowel disease: the Florence study
}

\author{
D Palli, G Trallori, C Saieva, O Tarantino, E Edili, G D’Albasio, F Pacini, G Masala
}

\begin{abstract}
Background-A population based epidemiological study identified all the patients diagnosed with ulcerative colitis (UC) or Crohn's disease (CD) resident in the Florence area in the period 1978-1992.

Aims-To assess the mortality of unselected patients with inflammatory bowel disease (IBD) in a Mediterranean country.

Methods-Overall, 920 patients (689 UC and $231 \mathrm{CD})$ were followed until death or end of follow up (31 December 1996). Information on vital status was available for all except eight patients $(0.9 \%) ; 70$ deaths were identified ( 23 in patients with CD and 47 in patients with UC). Expected deaths were estimated on the basis of five year age group, gender, and calendar year national mortality rates. Standardised mortality ratios (SMR) and $95 \%$ confidence intervals were calculated.
\end{abstract}

Results-General mortality was significantly lower than expected in UC (SMR $0.6 ; 95 \%$ confidence interval 0.4 to 0.8 ), due to a reduced number of cardiovascular and, possibly, smoking related deaths. Cancers of the respiratory tract were significantly reduced in UC but tended to be increased in patients with CD. These latter patients had not only an increased cancer mortality but also a $\mathbf{4 0 \%}$ increased risk of dying for all causes already evident in the first five year follow up period and persisting thereafter. In contrast, in patients with UC, SMRs were initially very low but tended to increase steadily over the follow up period. Gastrointestinal deaths were particularly increased in patients with $C D$, but only moderately in those with UC. Overall, there was some evidence of a twofold increased mortality for colorectal cancer, the risk being highest for rectal cancers in patients with UC. A non-significant excess of deaths due to haemolymphopoietic malignancies and suicides was also observed.

Conclusions-This study, the first in a Mediterranean country, supports the existence of two divergent mortality patterns for patients with $U C$ and $C D$, possibly explained by differences in smoking habits and by a greater severity of CD.

(Gut 1998;42:175-179)
Keywords: ulcerative colitis; Crohn's disease; inflammatory bowel disease; epidemiology; mortality; cancer

Incidence and prevalence rates of inflammatory bowel disease (IBD) have been reported as increasing in most European countries, including the Mediterranean area. Careful planning of health care services provided by gastroenterology departments (including both inpatient and outpatient services) is urgently needed. Population based studies of mortality for these patients have been carried out only in northern European countries while the experience in southern Europe has been evaluated mostly on the basis of clinical series.

The recent increasing trend observed in the metropolitan area surrounding Florence ${ }^{1}$ provided the opportunity to study a large representative series of patients newly diagnosed at the beginning of what can be reasonably considered a "new" phenomenon, possibly with a more evident contrast between affected patients and the general population. This rising wave of IBD followed that already observed in high risk countries a few decades before and occurred in a period in which availability of advanced and reliable diagnostic techniques (including colonoscopy and double contrast enema) was widespread and easily accessible for the local population, in the frame of a free national health system. Clear diagnostic criteria were already well established and used by clinicians active in the Florence area; rational drug treatments were also available together with standardised protocols based on the earlier experience of northern European countries.

The aim of the study was to provide a reliable evaluation of the mortality experience of a relatively large population based cohort of patients with IBD in a Mediterranean country.

\section{Subjects and methods}

A previous population based epidemiological study identified all the patients aged at least 15 years with a diagnosis of ulcerative colitis or Crohn's disease resident in the metropolitan area of Florence in the period 1978-1992. At the National Census in 1991 the population included approximately 550000 residents above 14 years of age. The area is covered by a Cancer Registry and by a Regional Mortality Registry, both run locally at CSPO.

Overall, 920 patients were identified as residing in the area at any time in the study period with a diagnosis of IBD. All were 
Table 1 Mortality in the total cohort of 920 patients with IBD (overall follow up 9940 person years) by major groups of diagnostic categories

\begin{tabular}{llllll}
\hline Cause of death & ICD IX & $\begin{array}{l}\text { No of deaths } \\
\text { observed }\end{array}$ & No expected & SMR & $95 \%$ CI \\
\hline Neoplasms & $140-208$ & 23 & 28.28 & 0.81 & 0.5 to 1.2 \\
Cardiovascular diseases & $390-459$ & 22 & 37.23 & 0.59 & 0.4 to 0.9 \\
Respiratory diseases & $460-519$ & 0 & 5.5 & - & - \\
Gastrointestinal diseases & $520-579$ & 13 & 6.23 & 2.09 & 1.1 to 3.6 \\
Violent causes & $800-998$ & 4 & 5.41 & 0.74 & 0.2 to 1.9 \\
Other causes & & 8 & 9.36 & 0.85 & 0.4 to 1.7 \\
All deaths & $001-999$ & 70 & 92.01 & 0.76 & 0.6 to 0.96 \\
\hline
\end{tabular}

* Including infectious disease, diabetes $(\mathrm{n}=2)$, arthritis, AIDS, renal failure and two ill defined causes.

SMR, standardised mortality ratio; CI, confidence interval.

followed since enrolment until death or end of follow up (31 December 1996). The date of enrolment was defined as follows: date of diagnosis for 796 cases incident in the study period $(86.5 \%)$; 1 January 1978 or date of migration into the area for 124 period prevalent cases $(13.5 \%)$, diagnosed before the start of the study period or while residing elsewhere and who later migrated into the area.

Sixty seven patients $(7.3 \%)$ had migrated outside the study area and were individually followed by contacting the town offices in Tuscany or in other areas. Four patients had left the country and were censored at the date of migration abroad; four of the 63 patients who had migrated elsewhere in Italy could not be traced and were also censored. Overall, therefore, the vital status at the end of follow up was not available for eight patients that were considered for analysis only until the date of migration.

Links with local town offices and the Regional Mortality Registry allowed the identification of 70 deaths and the retrieval of all individual death certificates. Expected deaths were estimated on the basis of five year age group, gender, and calendar year specific national mortality rates. Standardised mortality ratios (SMR) were estimated for overall mortality and selected groups of causes including specific cancer sites; $95 \%$ confidence intervals (CI) were calculated based on the assumption of a Poisson distribution for deaths observed in follow up. Causes of death were classified according to the ninth edition of the International Classification of Diseases (ICD IX).

Analyses were first carried out for the whole cohort and then separately for each IBD type, gender, and five year follow up period. A small group of patients with a family history of IBD identified previously, within the same cohort, ${ }^{2}$ was also considered for separate analysis.

Kaplan-Meier survival curves for incident cases were estimated according to time interval since diagnosis. No correction was attempted to take into account surgical operations removing, totally or in part, the large bowel when estimating SMRs for colorectal cancer.

\section{Results}

Overall, 920 patients with IBD (689 ulcerative colitis and 231 Crohn's disease) were identified as residing in the area at any time during the period 1978-1992 and followed since enrolment until death or 31 December 1996. At the end of the study the vital status could not be assessed for eight patients $(0.9 \%)$.

A total of approximately 9940 person years was available for analysis, with a median follow up of 10.1 years. Male patients (410 ulcerative colitis and 115 Crohn's disease) provided a total of 5690 person years; females (279 ulcerative colitis and 116 Crohn's disease) contributed a total of 4250 person years. According to diagnosis, patients with ulcerative colitis and Crohn's disease provided 7380 and 2560 person years, respectively.

\section{GENERAL MORTALITY}

Table 1 shows the observed and the expected deaths in the whole IBD cohort and the resulting SMRs. General mortality was significantly reduced (SMR 0.76; 95\% CI 0.6 to 0.96) because of a strongly reduced mortality for cardiovascular diseases (SMR 0.59; 95\% CI 0.4 to 0.9 ). In contrast, a twofold increase was evident for the group of diagnostic categories including all non-malignant gastrointestinal diseases and related complications (SMR 2.09; 95\% CI 1.1 to 3.6 ).

No deaths due to respiratory disease were identified. The other diseases responsible for the death of eight patients included infectious disease, diabetes (two patients), arthritis, AIDS, renal failure, and two ill defined causes. Two deaths due to suicide were also identified in the group of violent causes (expected deaths 1.06).

Results of separate analyses by gender (based on 36 deaths in males and 34 in females) suggested an even lower total mortality in males, while female patients had an overall risk pattern similar to that of the general population.

General mortality was significantly lower than expected in patients with ulcerative colitis (SMR 0.62; 95\% CI 0.4 to 0.8), based on the observation of 47 deaths (table 2). This result was mainy due to a significantly reduced number of cardiovascular deaths (SMR 0.58; $95 \%$ CI 0.4 to 0.9 ); on the other hand, deaths due to gastrointestinal causes were only moderately increased.

Table 2 also presents results obtained for the subcohort of patients with Crohn's disease, based on 23 deaths observed in the study period. For general mortality a non-significant $40 \%$ increase was evident (SMR 1.36; 95\% CI 0.9 to 2.0 ). Deaths due to non-malignant gastrointestinal causes were significantly increased (SMR 4.31; 95\% CI 1.4 to 10.1), based on five 


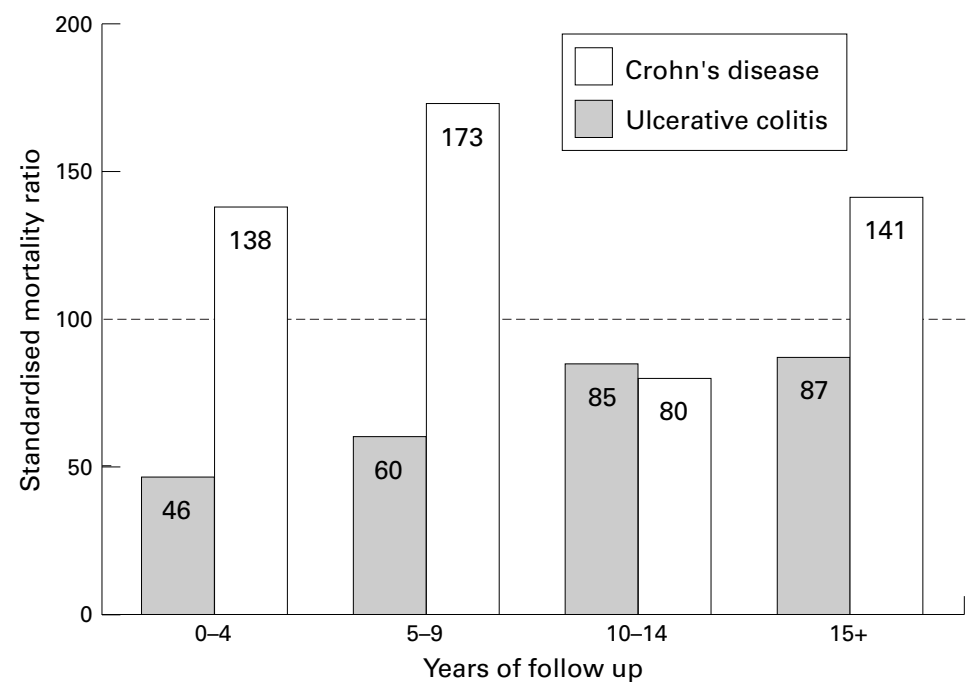

Figure 1 Total mortality SMRs for each five year follow up period by IBD type.

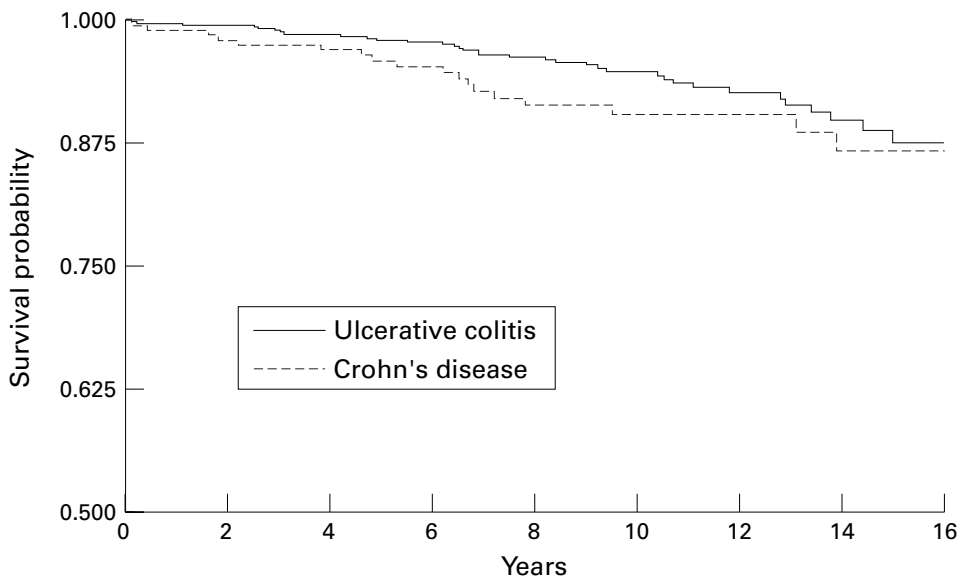

Figure 2 Kaplan-Meier survival curves of 796 incident patients with IBD by disease type.

cases (three specifically related to Crohn's disease while two were certified as due to liver cirrhosis).

According to the time interval since the start of follow up for each individual, general mortality tended to present two clearly distinct patterns in the two diseases. In patients with ulcerative colitis, mortality was particularly low at the start of follow up but steadily increased thereafter (fig 1). In contrast, patients with Crohn's disease showed increased SMRs from the start.
Figure 2 presents survival curves in the first 15 years of follow up for the 796 incident patients; patients with ulcerative colitis showed a better outcome than those with Crohn's disease. The number of patients at risk was as follows: five years, 529 patients with ulcerative colitis (98\% survival), 176 patients with Crohn's disease (95.9\% survival); 10 years, 246 patients with ulcerative colitis $(94.3 \%$ survival), 98 patients with Crohn's disease $(90.4 \%$ survival); and 15 years follow up, 73 patients with ulcerative colitis ( $87.6 \%$ survival), 45 patients with Crohn's disease (86.7\% survival).

Median age at death was, overall, 71 years, with male patients with IBD dying earlier than affected women (70.5 and 74.5 years, respectively). According to IBD type, Crohn's disease and patients with ulcerative colitis presented a median age at death of 60 and 73 years, respectively. A subgroup of 48 patients with a verified positive IBD family history did not show any specific pattern; only two cardiovascular deaths were observed.

CANCER MORTALITY

Cancer mortality in the whole IBD cohort (23 deaths) was slightly lower than expected and did not show any specific pattern when the combined analysis considered cancer distribution at different sites.

According to IBD type, however, total cancer mortality tended to be increased in patients with Crohn's disease (SMR 1.90; 95\% CI 0.9 to 3.5), based on 10 cases (table 3), but was significantly decreased in ulcerative colitis on the basis of 13 deaths (table 3 ).

The increase in cancer mortality in patients with Crohn's disease was only slightly affected after exclusion of colorectal cancer mortality (SMR 1.89). Exclusion of colorectal cancer deaths caused a further reduction in cancer mortality for patients with ulcerative colitis (SMR 0.43; 95\% CI 0.2 to 0.8 ).

Cancers of the respiratory tract were strongly and significantly reduced in ulcerative colitis (SMR 0.16; 95\% CI 0.1 to 0.9), and tended to be increased in patients with Crohn's disease. This effect was particularly evident in women with Crohn's disease (two deaths due to lung cancer; 0.2 would have been expected).

Overall, considering both diseases, there was only limited evidence of an increased mortality from colorectal cancer (SMR 2.0; 95\% CI 0.6 to 4.6$)$; the increase was highest for rectal

Table 2 Mortality in the two subcohorts of 689 patients with ulcerative colitis (7380 person years) and 231 with Crohn's disease (2560 person years) by major groups of diagnostic categories

\begin{tabular}{|c|c|c|c|c|c|c|c|c|c|c|}
\hline & \multicolumn{5}{|c|}{ Ulceratve colitis } & \multicolumn{5}{|c|}{ Crohn's disease } \\
\hline & $I C D I X$ & $\begin{array}{l}\text { No of deaths } \\
\text { observed }\end{array}$ & $\begin{array}{l}\text { No } \\
\text { expected }\end{array}$ & $S M R$ & $95 \% C I$ & $I C D I X$ & $\begin{array}{l}\text { No of deaths } \\
\text { observed }\end{array}$ & No expected & $S M R$ & $95 \% C I$ \\
\hline Neoplasms & $140-208$ & 13 & 23.02 & 0.56 & 0.3 to 0.96 & $140-208$ & 10 & 5.26 & 1.90 & 0.9 to 3.5 \\
\hline Cardiovascular diseases & $390-459$ & 18 & 30.64 & 0.58 & 0.4 to 0.9 & $390-459$ & 4 & 6.6 & 0.61 & 0.2 to 1.5 \\
\hline Respiratory diseases & $460-519$ & 0 & 4.64 & - & - & $460-519$ & 0 & 0.86 & - & - \\
\hline Gastrointestinal & $520-579$ & 8 & 508 & 157 & 07 to 31 & $520-579$ & 5 & 1.16 & 431 & 14 to 101 \\
\hline Violent causes & $800-998$ & 3 & 4.23 & 0.71 & 0.1 to 2.1 & $800-998$ & 1 & 1.17 & 0.85 & 0.01 to 4.7 \\
\hline Other causes & & $5^{\star}$ & 7.55 & 0.66 & 0.2 to 1.5 & & $3+$ & 1.82 & 1.65 & 0.3 to 4.8 \\
\hline All deaths & 001-999 & 47 & 75.16 & 0.62 & 0.4 to 0.8 & 001-999 & 23 & 16.87 & 1.36 & 0.9 to 2.0 \\
\hline
\end{tabular}

* Including diabetes $(n=2)$, arthritis, AIDS and one ill defined cause.

t Including infectious disease, renal failure and one ill defined cause.

SMR, standardised mortality ratio; CI, confidence interval. 
Table 3 Cancer mortality in the two subcohorts of 689 patients with ulcerative colitis and 231 with Crohn's disease

\begin{tabular}{|c|c|c|c|c|c|c|c|c|c|c|}
\hline \multirow[b]{2}{*}{ Cancer site } & \multicolumn{5}{|c|}{ Ulcerative colitis } & \multicolumn{5}{|c|}{ Crohn's disease } \\
\hline & $I C D I X$ & $\begin{array}{l}\text { No of deaths } \\
\text { observed }\end{array}$ & $\begin{array}{l}\text { No } \\
\text { expected }\end{array}$ & $S M R$ & $95 \% C I$ & $I C D I X$ & $\begin{array}{l}\text { No of deaths } \\
\text { observed }\end{array}$ & $\begin{array}{l}\text { No } \\
\text { expected }\end{array}$ & $S M R$ & $95 \% C I$ \\
\hline Digestive system & $150-159$ & 6 & 7.97 & 0.75 & 0.3 to 1.6 & $150-159$ & 2 & 1.83 & 1.2 & 0.1 to 3.9 \\
\hline Stomach & 151 & 1 & 2.28 & 0.44 & 0.01 to 2.4 & 151 & 1 & 0.51 & 1.96 & 0.02 to 11.0 \\
\hline Colon & 153 & 1 & 1.33 & 0.75 & 0.01 to 4.2 & 153 & 1 & 0.32 & 3.12 & 0.04 to 17.4 \\
\hline Rectum & 154 & 3 & 0.69 & 4.35 & 0.9 to 12.7 & 154 & 0 & 0.17 & - & - \\
\hline Liver & 155 & 1 & 1.69 & 0.59 & 0.01 to 3.3 & 155 & 0 & 0.39 & - & - \\
\hline Respiratory system & $160-165$ & 1 & 6.06 & 0.16 & 0.01 to 0.9 & $160-165$ & 3 & 1.14 & 2.63 & 0.5 to 7.7 \\
\hline Lung & 162 & 1 & 5.84 & 0.17 & 0.01 to 0.9 & 162 & 3 & 1.09 & 2.75 & 0.5 to 8.0 \\
\hline Breast & 174 & 2 & 1.27 & 1.57 & 0.2 to 5.7 & 174 & 1 & 0.49 & 2.04 & 0.03 to 11.3 \\
\hline Uterus & 179,182 & 1 & 0.37 & 2.7 & 0.03 to 15.0 & 179,182 & 1 & 0.15 & 6.66 & 0.09 to 37.1 \\
\hline Prostate & 185 & 1 & 0.87 & 1.15 & 0.02 to 6.4 & 185 & 1 & 0.12 & 8.33 & 0.1 to 46.4 \\
\hline Brain & 191 & 0 & 0.55 & - & - & 191 & 1 & 0.15 & 6.66 & 0.1 to 37.1 \\
\hline \multicolumn{11}{|l|}{ Haematopoietic } \\
\hline system & $200-208$ & 2 & 1.51 & 1.32 & 0.1 to 4.8 & $200-208$ & 1 & 0.38 & 2.63 & 0.03 to 14.7 \\
\hline Myeloma & 203 & 0 & 0.26 & - & - & 203 & 1 & 0.07 & 14.28 & 0.2 to 79.5 \\
\hline \multicolumn{11}{|l|}{ Non-Hodgkin's } \\
\hline lymphoma & 200,202 & 1 & 0.44 & 2.27 & 0.03 to 12.6 & 200,202 & 0 & 0.11 & - & - \\
\hline Leukaemia & $204-208$ & 1 & 0.7 & 1.43 & 0.02 to 7.9 & $204-208$ & 0 & 0.18 & - & - \\
\hline All cancer deaths & $140-208$ & 13 & 23.02 & 0.56 & 0.3 to 0.96 & $140-208$ & 10 & 5.26 & 1.9 & 0.9 to 3.5 \\
\hline
\end{tabular}

SMR, standardised mortality ratio; CI, confidence interval.

cancers in patients with ulcerative colitis (SMR 4.3 ; $95 \%$ CI 0.9 to 12.7 ), based on three cases. No deaths due to a small bowel tumour were identified.

A non-significant excess of haemolymphopoietic malignancies was observed (three cases versus 1.9 expected), without any specific clustering. Only one death due to cancer of the hepatobiliary system was observed (2.1 expected).

\section{Discussion}

The results of this population based study, the first carried out in a Mediterranean country, are in agreement with those obtained in similar larger studies in northern Europe, but suggest two specific and divergent patterns for these cohorts of Italian patients with ulcerative colitis and Crohn's disease. We have recently shown that IBD incidence rates increased in this population over a 15 year period in the Florence metropolitan area ${ }^{1}$; a capture recapture analysis also showed that our case ascertainment was quite accurate in comparison to other studies. ${ }^{3}$ Follow up of this large series was practically complete and no selected loss occurred.

An overall mortality lower than the general population in patients with ulcerative colitis was not an unexpected finding in view of the relatively short time interval since diagnosis and the higher socioeconomic level of these patients. ${ }^{4}$ Most reports have described a low or only slightly increased mortality for patients with ulcerative colitis. ${ }^{5-8}$ A few northern European studies have, on the other hand, reported a moderately increased mortality. ${ }^{9-11}$ It is interesting, however, that in our study mortality showed a steadily increasing trend for patients with ulcerative colitis over the follow up period.

A specific pattern of smoking habits, traditionally reported as negatively associated with ulcerative colitis, ${ }^{12}{ }^{13}$ probably contributed to a reduced mortality for a group of smoking related causes including lung cancer and cardiovascular deaths, particularly relevant among young adults. Increased mortality from respiratory diseases in ulcerative colitis has been reported by others, ${ }^{81011}$ but it has been associated with asthma more than bronchitis and emphysema. On the other hand, long term treatments based on salicylates might also have contributed to a reduced cardiovascular mortality as suggested by another study. ${ }^{10}$

The smoking habits of patients with Crohn's disease have been consistently reported as characterised by a much higher frequency of current smokers in comparison to the general population. $^{12} 13$

An excess risk of mortality for lung cancer, however, has not been reported to date but an incidence study has shown an increased risk for lung cancer. ${ }^{14}$ Smoking has also been associated with an increased probability of recurrence of the disease. ${ }^{15}$ Two clearly divergent lung cancer mortality patterns for patients with ulcerative colitis and Crohn's disease were evident in this series, with a fivefold reduction and a threefold increase in risk, respectively. A reduced risk for lung cancer in patients with ulcerative colitis had already been reported in two cancer incidence studies from the UK and Denmark. ${ }^{16}{ }^{17}$

Patients with Crohn's disease showed an increased mortality in the first five year period of follow up which persisted in the following years, in agreement with most reports. $.^{10} 1118-20$ A recent study followed a series of 322 newly diagnosed patients with Crohn's disease in a single referral centre in southern Italy $^{21}$; no evidence of increased mortality was found but results were based on only nine deaths identified in an eight year follow up period.

Total cancer mortality tended to be increased in Crohn's disease, suggesting the existence of a pattern of increased exposure to environmental carcinogens or some specific susceptibility. In contrast, patients with ulcerative colitis had a significantly reduced risk of cancer mortality.

Only modest evidence of increased mortality from large bowel cancer was found in the overall series. Again, the follow up is relatively short but one has to consider the proportion of patients who had undergone surgery and also that long term maintenance treatment has been 
advocated by most local clinicians..$^{22}$ A reduced risk for colorectal cancer in patients with ulcerative colitis actively treated with anti-inflammatory drugs has been reported recently. ${ }^{23}$ Overall, however, population based studies in the past decade have reported a substantially lower colorectal cancer mortality ${ }^{10} 11$ in comparison to earlier estimates.

An increased risk for colorectal cancer has been consistently reported in most population based cancer incidence studies in patients with ulcerative colitis, ${ }^{81724}$ with only a few exceptions. ${ }^{6} \mathrm{~A}$ strong increase in the incidence of colorectal cancer has been reported in clinical series of patients with ulcerative colitis followed by referral centres ${ }^{1625}{ }^{26}$; similar studies have also reported increased risks for patients with both Crohn's disease and ulcerative colitis and extensive colitis. ${ }^{27}$ In contrast, patients with Crohn's disease have not shown an increased risk of colorectal cancer in population based studies. ${ }^{14}{ }^{18}$ An excess risk of death by suicide has been reported by several studies, ${ }^{1128}$ but not by others. ${ }^{10}$ In this series a twofold increased risk was evident.

In conclusion, the follow up results of this first relatively large population based series of patients with IBD identified in a Mediterranean country have shown two clearly divergent mortality patterns for ulcerative colitis and Crohn's disease. Smoking habit seems to contribute significantly to the increased mortality observed in Crohn's disease. Perhaps when considering the other negative effects on the clinical course of the disease, physicians should also urge their patients with Crohn's disease to give up smoking and provide them with adequate support to achieve this.

The authors acknowledge the support and cooperation of the local association of patients with IBD (AMICI), the Florence the Florence IBD Study Group, including many dedicated physicians of local hospitals (in particular Gabriele Bardazzi, A O Careggi, and (RMR-CSPO, Florence), and Chiara Zappitello for editorial assistance. The study was supported by Regione Toscana.

1 Trallori G, Palli D, Saieva C, et al. A population-based study of inflammatory bowel disease in Florence over 15 years of inflammatory bowel disease in Florence ove

2 Palli D, Saieva C, Trallori G, et al. A population based study of familial clustering of IBD in Florence. European fournal of Public Health 1997;7:109-12.

3 Palli D, Masala G, Saieva C. Population-based studies of IBD incidence in Italy and capture-recapture methods [letter]. Int $\mathcal{F}$ Epidemiol 1997;26:904-5.

4 Russel GVM, Stockbrugger RW. Epidemiology of inflammatory bowel disease: an update. Scand $\mathcal{F}$ Gastroentero 1996;31:417-27.
5 Stonnington CM, Phillips SF, Zinsmeister AR, Melton III LJ. Prognosis of chronic ulcerative colitis in a community. LJ. Prognosis of chro

6 Langholz E, Munkholm P, Davidsen M, Binder V. Colorectal cancer risk and mortality in patients with ulcerative colitis. Gastroenterology 1992;103:1444-51.

7 Probert CSJ, Jayanthi V, Wicks ACB, Mayberry JF. Mortality in patients with ulcerative colitis in Leicestershire, 1972-1989. An epidemiological study. Dig Dis Sci 1993;38:538-41.

8 Stewenius J, Adnerhill I, Anderson $\mathrm{H}$, et al. Incidence of colorectal cancer and all cause mortality in non-selected patients with ulcerative colitis and indeterminate colitis in Malmo, Sweden. Int f Colorectal Dis 1995;10:117-22.

9 Brostrom O, Monsen U, Nordenwall B, Sorstad J, Hellers G. Prognosis and mortality of ulcerative colitis in Stockholm county, 1955-1979. Scand f Gastroenterol 1987; 22:907-13.

10 Ekbom A, Helmick CG, Zack M, Holmberg L, Adami H-O. Survival and cause of death in patients with inflammatory Survival and cause of death in patients with inflammatory
bowel disease: a population based-study. Gastroenterology 1992;103:954-60.

11 Persson P-G, Bernell O, Leijonmarck C-E, Farahmand BY, Hellers G, Ahlbom A. Survival and cause-specific mortality in inflammatory bowel disease: a population based cohort study. Gastroenterology 1996;110:1339-45.

12 Franceschi S, Panza E, La Vecchia C, Parazzini F, Decarli A, Bianchi Porro G. Nonspecific inflammatory bowel disease and smoking. Am f Epidemiol 1987;125:445-52.

13 Tobin MV, Logan RFA, Langman MJS, McConnell RB, Gilmore IT. Cigarette smoking and inflammatory bowel disease. Gastroenterology 1987;93:316-21.

14 Persson P-G, Karlen P, Bernell O, et al. Crohn's disease and cancer: a population based cohort study. Gastroenterology 994;107:1675-9.

15 Cottone M, Rosselli M, Orlando A, et al. Smoking habits and recurrence in Crohn's disease. Gastroenterology 1994; 106:643-8.

16 Prior P, Gyde SN, Macartney JC, Thompson H, Waterhouse JAH, Allan RN. Cancer morbidity in ulcerative colitis. Gut 1982;23:490-7.

17 Mellemkjaer L, Olsen JH, Frisch M, Johansen C, Gridley G, McLaughlin JK. Cancer in patients with ulcerative colitis. Int f Cancer 1995;60:330-3.

18 Probert CSJ, Jayanthi V, Wicks ACB, Mayberry JF. Mortality from Crohn's disease in Leicestershire, 19721989: an epidemiological community based study. Gut 1992;33:1226-8.

19 Munkholm P, Langholz E, Davidsen M, Binder V. Intestinal cancer risk and mortality in patients with Crohn's disease. Gastroenterology 1993;105:1716-23.

20 Weterman IT, Biemond I, Pena AS. Mortality and causes of death in Crohn's disease. Review of 50 years' experience in death in Crohn's disease. Review of 50 years' experi
Leiden University Hospital. Gut 1990;31:1387-90.

21 Cottone M, Magliocco A, Rosselli M, et al. Mortality in patients with Crohn's disease. Scand 7 Gastroenterol 1996;31:372-5.

22 d'Albasio G, Pacini F, Camarri E, et al. Combined therapy with 5ASA tablets and enemas for maintaining remission in ulcerative colitis: results at 12 months. Abstract book 1113 Digestive Disease Week, San Diego, USA, 1995.

23 Pinczowski D, Ekbom A, Baron J, Yuen J, Adami H-O. Risk factors for colorectal cancer in patients with ulcerative colitis: a case-control study. Gastroenterology 1994;107: $117-20$

24 Ekbom A, Helmick CG, Zack M, Holmberg L, Adami H-O. Ulcerative colitis and colorectal cancer. A population based study. N Engl 7 Med 1990;323:1228-33.

25 Gyde S-N, Prior P, Allan R-N, et al. Colorectal cancer in ulcerative colitis: a cohort study of primary referrals from three centres. Gut 1988;29:206-17.

26 Kvist N, Jacobsen O, Kvist H-KN, et al. Malignancy in tenterol 1989;24:497-506.

27 Gillen C-D, Walmsley R-S, Prior P, Andrews HA, Allòn $\mathrm{RN}$. Ulcerative colitis and Crohn's disease: a comparison of the colorectal cancer risk in extensive colitis. Gut 1994;35: $1590-2$

28 Prior P, Gyde SN, Cooke WT, Waterhouse JAH. Mortality in Crohn's disease. Gastroenterology 1981;89:307-12. 